\title{
Cue restricted smoking increases quit rates with varenicline
}

\author{
Jaqueline R. Scholz', Tania O. Abe', Patricia V. Gaya', Bianca Bellini', Iana R. A. de Moraes', Juliana R. Santos², Paulo \\ R. X. Tomaz², Paulo C. Jr. de Lima Santos ${ }^{3}$, Serena Tonstad ${ }^{4}$
}

\begin{abstract}
INTRODUCTION Varenicline effectively helps smokers quit by reducing withdrawal symptoms and blocking the reward of smoking. However, most quitters return to smoking within one year. 'Cue Restricted Smoking' is a behavioral technique designed to increase quit rates by asking smokers attempting to quit to restrict smoking to the standing position, while alone, in an isolated area facing a wall, with the cigarette as the only stimulus.

METHODS Using retrospective clinic records we compared quit rates in 281 smokers ( $50 \%$ males) instructed in the cue restricted smoking cessation method during 2016-2018 to quit rates in 324 smokers (46\% males) advised to completely stop smoking on the target quit date which we previously used during 2011-2014. All were prescribed varenicline for 12 weeks alone, with the addition of bupropion if needed after 4 weeks. Follow-up consisted of behavioral support at 4-6 visits during active drug treatment and telephone counselling at 24 and 52 weeks. The smoking cessation rate was confirmed with exhaled carbon monoxide at the clinic visit at 12 weeks and only by telephone at 52 weeks.

RESULTS The mean age of smokers was 49 years in both groups and the number of cigarettes smoked daily was similar (18/day in the cue restricted vs 19 /day in the target quit day group). The smoking cessation rate at 12 weeks was $75 \%$ in the cue restricted versus $45 \%$ in the target quit day group (relative risk, $R R=1.8 ; 95 \%$ CI: $1.4-2.2, \mathrm{p}<0.001)$. At 52 weeks the quit rate was $65 \%$ vs $34 \%$, respectively $(\mathrm{RR}=1.9 ; 95 \% \mathrm{CI}: 1.5-2.4, \mathrm{p}<0.001)$.

CONCLUSIONS Cue restricted smoking was associated with a substantially increased chance of quitting compared with standard advice during treatment with varenicline. These results should be further studied in a randomized controlled trial.
\end{abstract}

\section{AFFILIATION}

1 Department of Preventive Medicine, Heart Institute, University of Sao Paulo, Sao Paulo, Brazil

2 Laboratory of Genetics and Molecular Cardiology, Heart Institute, University of Sao Paulo, Sao Paulo, Brazil

3 Department of Pharmacology, Paulista School of Medicine, Federal University of Sao Paolo, Sao Paulo, Brazil

4 Department of Preventive Cardiology, Oslo University

Hospital, Oslo, Norway

CORRESPONDENCE TO Jaqueline R. Scholz. Department of Preventive Medicine, Heart Institute, University of Sao Paulo, Dr. Enéas Carvalho de Aguiar, 44 Cerqueira César, SP 05403900, Sao Paulo, Brazil. E-mail: jaquelineincor@yahoo.com.br

\section{KEYWORDS}

smoking cessation, nicotine dependence, varenicline, behavioral technique, target quit day

Received: 25 August 2020 Revised: 15 February 2021

Accepted: 21 February 2021

\section{INTRODUCTION}

Cigarette smoking is the leading preventable cause of morbidity and mortality worldwide, and major risk factor for cardiovascular disease ${ }^{1}$. Comprehensive tobacco cessation treatment is a critical component of the clinical care for individuals with or at risk for cardiovascular disease ${ }^{2}$. Tobacco use can be characterized as a chronic relapsing substance use disorder that is sustained by addiction to nicotine ${ }^{3}$. Pharmacotherapy acts synergistically with behavioral counseling to increase quit rates ${ }^{4}$. Varenicline is proven to be more effective in promoting smoking cessation than NRT (nicotine replacement therapy) or bupropion ${ }^{5}$ as single drug treatment, though combined NRT may be as effective as varenicline ${ }^{6}$. As a partial agonist of the $a 4 \beta 2$ acetylcholine receptor ${ }^{7}$, varenicline activates this nicotinic receptor, and thereby reducing the intensity of nicotine withdrawal symptoms. At the same time, it binds tightly to the nicotine receptor, preventing receptor binding by nicotine from cigarette smoke and reducing the rewarding effects of smoking. This antagonism effect 
results in reduced pleasure from smoking and is believed to explain why some smokers reduce their cigarette consumption even before their designated quit day ${ }^{7}$. However, the best cessation results achieved with varenicline plus behavioral counseling are less than $45 \%$ during the period of varenicline use (12 weeks) and less than $30 \%$ in the follow-up period of up to one year after starting treatment ${ }^{8,9}$.

In our effort to improve this scenario, in 2015 we initiated a new behavioral method to assist smokers treated with varenicline. This idea was born from the observation that some smokers using varenicline noticed loss of pleasure from smoking when using this drug and thereby reduced consumption and stopped. However, others did not notice this effect. We also observed that some of these smokers associated pleasurable behaviors with smoking, and the cigarette acted as just one element of their smoking ritual. So, some smokers continued to smoke even without the reward of smoking. Considering all these observations, we adopted a novel method that does not require the smoker to set a date to stop smoking nor is the smoker asked to avoid everyday situations or triggers. It allows the smoker to smoke as needed, using only the new model based on control tactics. The basic assumption is that smoking is associated with or controlled by stimulus environmental cues and that these cues contribute to the persistence of the habit. Treatment involves gradual elimination of smoking through programmed restriction of the range of stimuli that lead to smoking ${ }^{10}$. We called this model 'Cue Restricted Smoking' (CRS). We asked smokers attempting to quit to restrict smoking to the standing position, while alone, in an isolated area facing a wall, with the cigarette as the only stimulus. This model has been applied in all smokers receiving varenicline treatment since January 2016 in our Smoking Cessation Program.

The objective of this observational retrospective study in the real-life setting was to evaluate the quit rate observed with CRS versus the usual method of setting a quit date, 'Target Quit Date' (TQD) approach, to stop smoking in smokers treated with varenicline.

\section{METHODS}

\section{Study design}

We conducted a retrospective study among cigarette smokers who were referred by their physician or were self-referred to the outpatient smoking cessation program offered by the Heart Institute, University of São Paulo, Brazil, between January 2011 and December 2018. During this entire period (starting from 2008) a structured clinical protocol for smoking cessation has been implemented to standardize treatment. The aim of this study was to compare smoking cessation rates between two methods of behavioral support implemented in addition to drug treatment.

\section{Strategy for choice of drugs}

Men and women who smoked at least 5 cigarettes/ day and agreed to treatment were offered the combination of motivational support and effective drug therapy. All drugs prescribed were paid by the smoker. Varenicline was established as the initial drug treatment using a standard dosage of $0.5 \mathrm{mg}$ once daily for 3 days, increasing to $0.5 \mathrm{mg}$ twice daily for days 4 to 7 , and then to the maintenance dose of 1 $\mathrm{mg}$ twice daily for a total of 12 weeks. Bupropion starting with the dose of $150 \mathrm{mg} /$ day was added if the smoker did not achieve cessation after 4 weeks of varenicline and was maintained until 12 weeks, in line with preliminary studies showing that the combination may be more effective than single drug therapy ${ }^{11}$. In addition to recording previous psychiatric diagnoses, the treatment team asked the smoker about current anxiety or depressive symptoms and started treatment with a serotonin reuptake inhibitor, most often escitalopram $10 \mathrm{mg}$ q.d, if clinically indicated in smokers not currently treated for these conditions for 8-12 weeks or as needed ${ }^{12}$.

Follow-up was planned as five clinic visits during the 12 weeks of treatment. After the initial visit, the following visits of which all included behavioral support were at 2, 4, 6, 8 and 12 weeks. Vital signs and carbon monoxide concentration in exhaled air were obtained at each visit. After 12 weeks, participants were contacted by telephone at 24 and 52 weeks for further support and follow-up. At each visit or telephone consultation, information on use of cigarettes or other nicotine products was queried and recorded as well as side effects or other relevant problems associated with quitting, and the reasons for relapse. We have not included data from the 24 weeks visit in the current report as the time point 
was not considered a primary outcome. Smokers, who dropped out of the in-person consultations, were considered treatment failures and were counted as smokers in the analyses.

\section{Motivational support}

Between January 2011 and December 2014 smokers starting varenicline were asked to quit smoking using the conventional strategy of a target quit date scheduled between the 8 th and 14th day of varenicline use. They were asked to avoid situations that triggered an intense desire to smoke ${ }^{10}$, like drinking coffee or alcohol, thinking about times of the day one is likely to smoke (e.g. first thing in the morning or after meals) and then planning something to distract oneself when the urge strikes ${ }^{4}$ (e.g. by leaving the situation that triggered the urge or deep breathing). This counseling was carried out by the doctor during the medical consultation, during approximately 10 minutes, aiming to encourage the patient to indicate why quitting is personally relevant, being as specific as possible. In addition, the smoker was asked to identify potential negative consequences of tobacco use and benefits of stopping its use as well as personal barriers to success.

Starting in January 2016, the strategy of quitting on the target quit day was ended and substituted with CRS. As previously, the participant was free to smoke $a d$ lib in any situation or place during the first 8 days of treatment, but from day 8 of varenicline treatment smokers were advised that they could continue to smoke as desired but with the restriction of smoking only when standing completely alone, in an area isolated from other persons, facing a wall, without any kind of stimulus, except the cigarette itself (Figure 1). So, while smoking was allowed, it had to be done with this restriction. Further clarifications were that while intake of alcohol or other drinks such as coffee was allowed, smoking at the same time as eating and drinking was prohibited to avoid any cues or triggers related to food and drink. This counseling was also carried out by the doctor during the medical consultation, during approximately 10 minutes, following the same procedure as described before.

\section{Data collection}

All smokers were treated by the routine medical staff. The protocol included the establishment of an electronic database for the registration of relevant demographic and clinical variables of all treated smokers entitled 'Programa de Assistencia ao Fumante' (www.pafweb.com.br). At inclusion, participants were asked questions regarding: 1) sociodemographic characteristics including gender, age, ethnicity, educational level, and social economic status; 2) clinical and psychiatric co-morbidities; 3) concomitant drug treatments; 4) tobacco history and current use; and 5) previous smoking cessation treatment.

Until 2015, a previous diagnosis of psychiatric comorbidities assessed by a psychiatrist was recorded in the medical notes. From 2015, we included in the medical record current clinical diagnostic of anxiety and depression evaluated during smoking cessation treatment.

Search in the databank showed that 324 smokers were treated between January 2011 to December 2014 using the standard TQD approach while 281 smokers were treated using the CRS approach from January 2016 to December 2018. We excluded smokers treated during 2015, because there was a transition between the conventional TQD to the CRS method during that year.

The primary outcome of the study was continuous

\section{Figure 1. 'Cue Restricted Smoking' position}

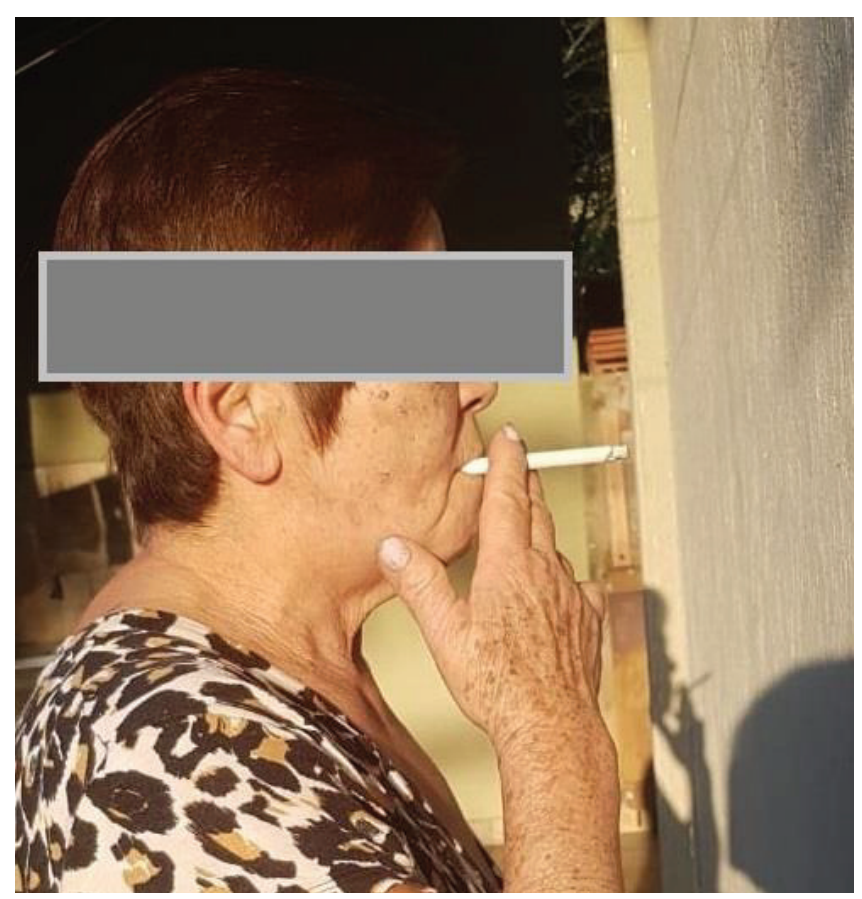


abstinence rate between the 4 -week period starting with the onset of week 9 and end of week 12 of varenicline treatment, confirmed through carbon monoxide in exhaled air $(\mathrm{CO}<4 \mathrm{ppm})$. Secondary outcomes were continuous abstinence rate at 52 weeks as well as reasons for lack of success and reasons for relapse between the period of time after week 12 to week 52. Possible categories for lack of success were: intense anxiety symptoms; side effects; stressful situations; lack of compliance; abstinence symptoms; cost; weight gain; interruption of treatment for example due to adverse events or depressive symptoms, or dropout from treatment. Possible categories leading to relapse included: intense anxiety symptoms; lapses; stressful situations; weight gain or depressive symptoms. Some smokers did not mention the reason, so were categorized as 'not mentioned'.

\section{Statistical analysis}

We analyzed the data using IBM SPSS 21 Version.
Categorical data were expressed in frequency, and proportions, and continuous data as mean and standard deviation. The association between categorical variables was assessed using the $\chi^{2}$ test or Fisher's exact test for comparative analysis of the demographic and clinical characteristics according to treatment response (success and continuous smoking). For quantitative variables, Student's t-test or Mann-Whitney (in case of non-normal distribution accessed via Kolmogorov-Smirnov and Shapiro-Wilk tests) were performed. A $\mathrm{p}<0.05$ was considered statistically significant.

\section{RESULTS}

\section{Participants}

Of the total of referred or self-referred smokers 605 of 740 smokers (82\%) started smoking cessation treatment with varenicline. Of those, 324 used the conventional technique of setting a quit date (TQD) and 281 used the cue restricted smoking (CRS) behavioral technique (Figure 2). Most of the smokers

Figure 2. Flowchart of smokers treated in 2011-14 with the 'Target Quit Date' method and smokers treated in 2016-18 with 'Cue Restricted Smoking' method
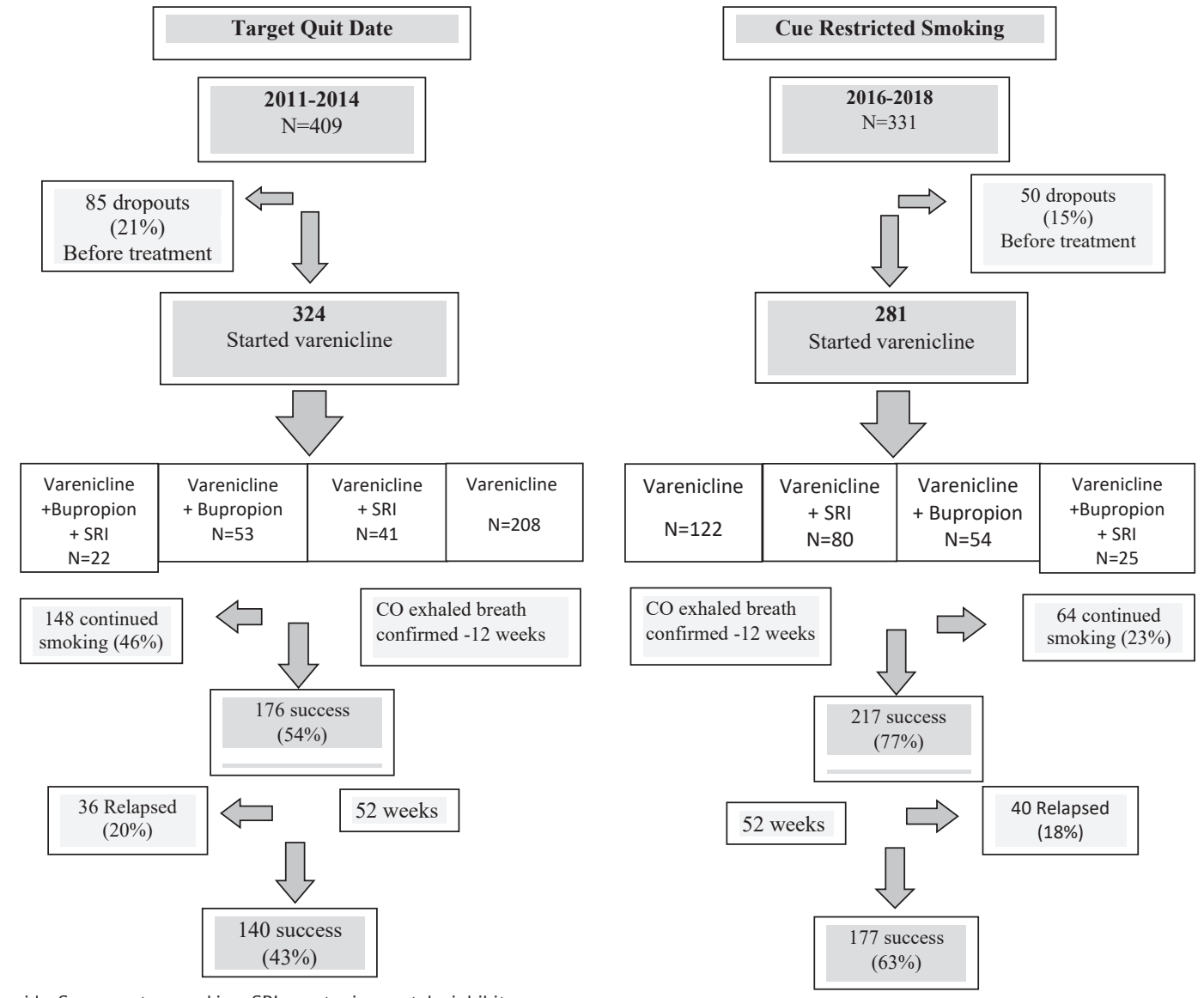

CO: carbon monoxide. Success: stop smoking. SRI: serotonin reuptake inhibitor. 
that achieved success in the CRS did so by week 4 after starting varenicline.

Demographic characteristics including gender, age, ethnicity, and marital status did not differ between the groups, as well as cigarettes/day and carbon monoxide concentration pre-treatment (Table 1). Concomitant clinical conditions were prevalent and similar in both groups, except for chronic obstructive pulmonary disease which was more common in the CRS group. Regarding psychiatric conditions, anxiety disorder was more prevalent in the CRS group, while depression was more prevalent in the TQD group.

\section{Outcome data}

At 12 weeks, $77 \%(217 / 281)$ of smokers in the CRS group reached the primary outcome between 9-12 weeks, confirmed through $\mathrm{CO}$ concentration in exhaled air, compared with 54\% (176/324) in TQD group, also confirmed through $\mathrm{CO}$ concentration in exhaled air. The relative risk (RR) showed a $42 \%$ higher chance to stop smoking with this compared to the standard technique ( $\mathrm{RR}=1.42 ; 95 \% \mathrm{CI}: 1.26-1.60$, $\mathrm{p}<0.001$ ) (Table 2). When we evaluated only smokers that used varenicline in monotherapy, 75\% (92/122) of the CRS group reached the primary outcome, while $42 \%(87 / 208)$ in the TQD group reached it, with an $\mathrm{RR}$ that was $80 \%$ higher in this group $(\mathrm{RR}=1.80$; 95\% CI: $1.49-2.18, \mathrm{p}<0.001$ ) (Table 2 ). There was no difference in smoking cessation rates between the groups in smokers treated with varenicline plus bupropion [CRS 81\% (44/54) vs TQD 75\% (40/53); $\mathrm{RR}=1.08$; 95\% CI: 0.88-1.32, $\mathrm{p}=0.45$ ] (Table 2 ).

There was no difference in smoking cessation rates between the groups in smokers treated with varenicline plus serotonin reuptake inhibitor $(\mathrm{RR}=0.98 ; 95 \%$ CI: $0.81-1.20, \mathrm{p}=0.71)$ [CRS $75 \%(65 / 80)$ vs TQD $78 \%(32 / 41)]$ (Table 2$)$, but these subgroups were comparatively small to the monotherapy group.

Regarding continuous abstinence rate at week 52, $63 \%(117 / 281)$ of smokers achieved this secondary endpoint in the CRS group versus $43 \%(140 / 324)$ in the TQD group ( $\mathrm{RR}=1.46$; 95\% CI: $1.25-1.70$, $\mathrm{p}<0.001)$ (Table3). Regarding smokers treated only with varenicline the $\mathrm{RR}$ was $90 \%$ higher in the CRS (79/122) versus the TQD (71/208) $(\mathrm{RR}=1.90 ; 95 \%$ CI: $1.51-1.2 .40, \mathrm{p}<0.001)$ (Table 3$)$. There was no difference in smoking cessation rates between the groups in smokers treated with varenicline plus bupropion ( $\mathrm{RR}=1.15$; 95\% CI: $0.84-1.56, \mathrm{p}=0.38)$ [CRS 65\% (35/54) vs TQD 56\% (30/53)] (Table 3).

Regarding smokers that were treated with a serotonin reuptake inhibitor in addition to varenicline (regardless of bupropion), there was no

Table 1. Demographic, clinical and psychiatric characteristics of smokers

\begin{tabular}{|c|c|c|c|}
\hline Characteristics & $\begin{array}{c}\text { Cue } \\
\text { Restricted } \\
\text { Smoking } \\
(n=281) \\
\%\end{array}$ & $\begin{array}{c}\text { Target } \\
\text { Quit Date } \\
\left(\begin{array}{c}n=324) \\
\%\end{array}\right.\end{array}$ & $p$ \\
\hline Gender (Male) & 49.8 & 45.7 & 0.35 \\
\hline Age (years), mean \pm SD & $48.7 \pm 12.6$ & $49.4 \pm 11.0$ & 0.83 \\
\hline Cigarettes/day, mean \pm SD & $18 \pm 6$ & $19 \pm 7$ & 0.17 \\
\hline $\begin{array}{l}\text { CO }(p p m) \text { (pre-treatment), } \\
\text { mean } \pm \text { SD }\end{array}$ & $17.8 \pm 4.1$ & $18.3 \pm 5$ & 0.09 \\
\hline Ethnicity (Caucasian descent) & 94.3 & 93.9 & 0.23 \\
\hline Marital status (Married) & 55.0 & 61.9 & 0.11 \\
\hline Baseline weight $(\mathrm{kg})$, mean \pm SD & $76.8 \pm 15.9$ & $74.3 \pm 20.1$ & 0.08 \\
\hline $\begin{array}{l}\text { Number of coexisting diseases, } \\
\text { mean } \pm \text { SD }\end{array}$ & $1.4 \pm 1.4$ & $1.2 \pm 1.2$ & 0.12 \\
\hline \multicolumn{4}{|l|}{ Medical situation } \\
\hline Hypertension & 17.8 & 19.4 & 0.68 \\
\hline Coronary artery disease & 3.9 & 4.0 & 1.00 \\
\hline Dyslipidemia & 17.4 & 17.0 & 0.97 \\
\hline Diabetes & 8.5 & 6.6 & 0.18 \\
\hline Stroke & 0.4 & 0.6 & 1.00 \\
\hline Hypothyroidism & 10.0 & 7.4 & 0.33 \\
\hline Congestive heart failure & 0.4 & 0.6 & 1.00 \\
\hline Arrhythmia & 2.1 & 1.9 & 1.00 \\
\hline Valvular heart disease & 0.4 & 0.3 & 1.00 \\
\hline Cancer & 0.4 & 0.3 & 1.00 \\
\hline $\begin{array}{l}\text { Chronic obstructive pulmonary } \\
\text { disease }\end{array}$ & 23.1 & 12.3 & 0.001 \\
\hline Asthma & 1.1 & 1.9 & 0.65 \\
\hline Gastritis & 3.2 & 3.4 & 1.00 \\
\hline Vascular insufficiency & 1.4 & 0.9 & 0.85 \\
\hline Obesity $(\geq 40$ kg/m²) & 2.5 & 1.9 & 0.80 \\
\hline Depression & 15.7 & 24.1 & 0.01 \\
\hline Bipolar disorder & 0.4 & 1.5 & 0.29 \\
\hline Panic disorder & 2.5 & 4.3 & 0.32 \\
\hline Schizophrenia & 0.4 & 0.3 & 1.00 \\
\hline Anxiety disorder & 24.9 & 7.4 & $<0.001$ \\
\hline Use of illicit drugs & 0.4 & 1.2 & 0.46 \\
\hline Abuse of alcohol & 1.1 & 2.5 & 0.33 \\
\hline
\end{tabular}


Table 2. Carbon monoxide-confirmed success rates at week 12 for smokers treated in 2011-2014 with the 'Target Quit Date' method and smokers treated in 2016-2018 with the 'Cue Restricted Smoking' method

\begin{tabular}{|c|c|c|c|c|}
\hline & $\begin{array}{c}\text { Success } \\
n \\
\%(95 \% \text { CI })\end{array}$ & $\begin{array}{c}\text { Continued smoking } \\
n \\
\%(95 \% \text { CI })\end{array}$ & RR $(95 \%$ CI $)$ & $p$ \\
\hline \multicolumn{5}{|l|}{ Overall } \\
\hline Cue Restricted Smoking ( $\mathrm{n}=281)$ & $\begin{array}{c}217 \\
77(72-82)\end{array}$ & $\begin{array}{c}64 \\
23(18-28)\end{array}$ & $1.42(1.26-1.60)$ & $<0.0001$ \\
\hline Target Quit Date $(n=324)$ & $\begin{array}{c}176 \\
54(49-60)\end{array}$ & $\begin{array}{c}148 \\
46(40-51)\end{array}$ & & \\
\hline \multicolumn{5}{|l|}{ Varenicline alone } \\
\hline Cue Restricted Smoking ( $n=122)$ & $\begin{array}{c}92 \\
75(67-83)\end{array}$ & $\begin{array}{c}30 \\
25(17-33)\end{array}$ & $1.80(1.35-1.83)$ & $<0.0001$ \\
\hline Target Quit Date $(n=208)$ & $\begin{array}{c}87 \\
42(35-49)\end{array}$ & $\begin{array}{c}121 \\
58(51-65)\end{array}$ & & \\
\hline \multicolumn{5}{|l|}{ Varenicline + Bupropion } \\
\hline Cue Restricted Smoking $(n=54)$ & $\begin{array}{c}44 \\
81(70-93)\end{array}$ & $\begin{array}{c}10 \\
19(7-30)\end{array}$ & $1.08(0.88-1.32)$ & 0.45 \\
\hline Target Quit Date $(n=53)$ & $\begin{array}{c}40 \\
75(63-88)\end{array}$ & $\begin{array}{c}13 \\
25(12-37)\end{array}$ & & \\
\hline \multicolumn{5}{|c|}{ Varenicline + Serotonin reuptake inhibitor } \\
\hline Cue Restricted Smoking $(n=80)$ & $\begin{array}{c}65 \\
75(65-85)\end{array}$ & $\begin{array}{c}14 \\
25(1-35)\end{array}$ & $0.98(0.81-1.20)$ & 0.71 \\
\hline Target Quit Date $(n=41)$ & $\begin{array}{c}32 \\
78(64-92)\end{array}$ & $\begin{array}{c}9 \\
22(8-36)\end{array}$ & & \\
\hline \multicolumn{5}{|c|}{ Varenicline + Bupropion + Serotonin reuptake inhibitor } \\
\hline Cue Restricted Smoking ( $\mathrm{n}=25)$ & $\begin{array}{c}65 \\
82(68-100)\end{array}$ & $\begin{array}{c}14 \\
18(0-32)\end{array}$ & $1.09(0.81-1.44)$ & 0.83 \\
\hline Target Quit Date $(n=22)$ & $\begin{array}{c}17 \\
77(57-97)\end{array}$ & $\begin{array}{c}5 \\
23(3-43)\end{array}$ & & \\
\hline
\end{tabular}

Table 3. Success rates at week 52 for smokers treated in 2016-2018 with the 'Cue Restricted Smoking' method and smokers treated in 2011-2014 with the 'Target Quit Date' method

\begin{tabular}{|c|c|c|c|c|}
\hline & $\begin{array}{c}\text { Success } \\
n \\
\%(95 \% \mathrm{CI})\end{array}$ & $\begin{array}{c}\text { Continued smoking } \\
n \\
\%(95 \% \text { CI })\end{array}$ & $\operatorname{RR}(95 \% \mathrm{CI})$ & $p$ \\
\hline \multicolumn{5}{|l|}{ Overall } \\
\hline Cue Restricted Smoking ( $n=281)$ & $\begin{array}{c}117 \\
63(57-69)\end{array}$ & $\begin{array}{c}104 \\
37(31-43)\end{array}$ & $1.46(1.25-1.70)$ & $<0.0001$ \\
\hline Target Quit Date $(n=324)$ & $\begin{array}{c}140 \\
43(38-49)\end{array}$ & $\begin{array}{c}184 \\
57(52-63)\end{array}$ & & \\
\hline \multicolumn{5}{|l|}{ Varenicline alone } \\
\hline Cue Restricted Smoking ( $n=122)$ & $\begin{array}{c}79 \\
65(56-74)\end{array}$ & $\begin{array}{c}43 \\
35(26-44)\end{array}$ & $1.90(1.51-2.40)$ & $<0.0001$ \\
\hline Target Quit Date $(\mathrm{n}=208)$ & $\begin{array}{c}71 \\
34(27-41)\end{array}$ & $\begin{array}{c}137 \\
66(59-73)\end{array}$ & & \\
\hline \multicolumn{5}{|l|}{ Varenicline + Bupropion } \\
\hline Cue Restricted Smoking ( $n=54)$ & $\begin{array}{c}35 \\
65(51-79)\end{array}$ & $\begin{array}{c}19 \\
35(21-49)\end{array}$ & $1.15(0.84-1.56)$ & 0.38 \\
\hline
\end{tabular}


Table 3. Continued

\begin{tabular}{|c|c|c|c|c|}
\hline & $\begin{array}{c}\text { Success } \\
n \\
\%(95 \% \text { CI })\end{array}$ & $\begin{array}{c}\text { Continued smoking } \\
n \\
\%(95 \% \mathrm{CI})\end{array}$ & $R R(95 \% \mathrm{CI})$ & $p$ \\
\hline Target Quit Date $(n=53)$ & $\begin{array}{c}30 \\
56(42-70)\end{array}$ & $\begin{array}{c}23 \\
44(30-58)\end{array}$ & & \\
\hline \multicolumn{5}{|c|}{ Varenicline + Serotonin reuptake inhibitor } \\
\hline Cue Restricted Smoking $(\mathrm{n}=80)$ & $\begin{array}{c}46 \\
58(47-69)\end{array}$ & $\begin{array}{c}34 \\
42(31-53)\end{array}$ & $0.98(0.71-1.35)$ & 0.91 \\
\hline Target Quit Date $(n=41)$ & $\begin{array}{c}24 \\
59(43-75)\end{array}$ & $\begin{array}{c}17 \\
41(25-57)\end{array}$ & & \\
\hline \multicolumn{5}{|c|}{ Varenicline + Bupropion + Serotonin reuptake inhibitor } \\
\hline Cue Restricted Smoking ( $n=25)$ & $\begin{array}{c}17 \\
68(48-88)\end{array}$ & $\begin{array}{c}8 \\
32(12-53)\end{array}$ & $1.0(0.67-1.48)$ & 0.99 \\
\hline Target Quit Date $(n=22)$ & $\begin{array}{c}15 \\
68(46-90)\end{array}$ & $\begin{array}{c}7 \\
32(10-54)\end{array}$ & & \\
\hline
\end{tabular}

Table 4. Outcomes of not success - dropout group, main reasons for not achieving success and reason to relapses after week 12 to week 52

\begin{tabular}{|c|c|c|}
\hline & $\begin{array}{c}\text { Target Quit } \\
\text { Date }(n=324) \\
n \%\end{array}$ & $\begin{array}{c}\text { Cue } \\
\text { Restricted } \\
\text { Smoking } \\
(n=281) \\
n \%\end{array}$ \\
\hline Dropout & $29(9)$ & $45(16)$ \\
\hline $\begin{array}{l}\text { Reasons for not achieving } \\
\text { success up to } 12 \text { weeks }\end{array}$ & $119(36)$ & $19(7)$ \\
\hline Not mentioned & $3(<1)$ & $3(1)$ \\
\hline Intense anxiety symptoms & $16(5)$ & $1(<1)$ \\
\hline Side effects & $25(8)$ & $2(<1)$ \\
\hline Stressful situations & $23(7)$ & $6(2)$ \\
\hline Lack of compliance & $45(14)$ & $7(2)$ \\
\hline Abstinence symptoms & $1(<1)$ & 0 \\
\hline Cost & $1(<1)$ & 0 \\
\hline Depressive symptoms & $3(<1)$ & 0 \\
\hline Weight gain & $2(<1)$ & 0 \\
\hline Success until 12 weeks & $176(54)$ & $217(77)$ \\
\hline Relapses after week 12 to week 52 & $36(20)$ & $40(18)$ \\
\hline Not mentioned & 0 & $3(8)$ \\
\hline Intense anxiety symptoms & 0 & $9(23)$ \\
\hline Lapses & $16(44)$ & $10(25)$ \\
\hline Stressful situations & $18(50)$ & $16(40)$ \\
\hline Weight gain & $1(2)$ & $1(2)$ \\
\hline Depressive symptoms & $1(2)$ & $1(2)$ \\
\hline
\end{tabular}

difference in smoking cessation rates between the methods $(\mathrm{RR}=0.98 ; 95 \% \mathrm{CI}: 0.71-1.35, \mathrm{p}=0.91)$ [CRS 58\% (46/80) vs TQD 59\% (24/41)] (Table 3).

As shown in Table 4, 29 of 324 (9\%) in the TQD group dropped out of the study, all before week 12 . In the CRS group, 45 of 281 (16\%) dropped out, also all before week 12 . Other reasons for not achieving abstinence and reasons for relapses are shown in Table 4. In the TQD group and in the CRS group the main reason for not achieving abstinence in the first 12 weeks was lack of compliance. The primary reason to relapse between weeks 12 and 52 in both groups was stressful situations (Table 4).

\section{DISCUSSION}

The evidence from our study indicates that CRS compared to the conventional TQD method promoted a significant increase in abstinence rates in smokers using varenicline both at 12 and 52 weeks. The conventional practice of setting a date to stopping smoking may present a barrier for some quitters. The CRS behavioral method may disable positive reinforcement from smoking and replace it with a null or unattractive effect. This technique may also fit well with varenicline's mechanism of action ${ }^{7}$, which is to block the pleasure of smoking. Our notion is that when the smoker inhales a cigarette in the "cue restricted position', without the presence of any pleasant external stimulus, it easier to perceive the loss of the pleasure of smoking with the assistance of 
varenicline. In this manner, stopping smoking occurs in a progressive and controlled steps by the smoker, without the sensation of failure. The smoker realizes that he or she can stop smoking without having to be stressed by or experience urges related to regular routines of everyday life.

Our results, though retrospective bring up the notion that the CRS method may be of particular use as a supplement to varenicline. In our data, we did not find differences in quit rates between the methods in smokers treated with varenicline and bupropion or varenicline and a serotonin uptake inhibitor. This may be due to the smaller size of the groups or due to other reasons. Further research will be needed to clarify this question.

CRS shares some elements of a gradual reduction in smoking during a quit attempt but adds the novelty of only smoking in a very limited environment. Reduction in tobacco smoking before attempting to quit is common (gradual cessation) ${ }^{13}$, but guidelines for health professionals recommend abrupt smoking cessation ${ }^{4}$. Recently, Lindson et al. ${ }^{14}$ completed a Cochrane systematic review and meta-analysis including 22 trials (9219 participants) of gradual versus abrupt smoking cessation and found neither approach produced superior longterm cessation outcomes. This was the case whether self-help or behavioral support was implemented and whether the quit attempt included nicotine replacement therapy, but the smokers were not using varenicline. In contrast, other studies showed that quitting smoking abruptly was more likely to lead to lasting abstinence than cutting down first, even for smokers who initially preferred to quit by gradual reduction ${ }^{15,16}$. As in the meta-analysis, varenicline was not used in these studies.

Regarding gradual reduction in smokers treated with varenicline, Ebbert at al. ${ }^{17}$ conducted a randomized study to compare varenicline versus placebo on smoking cessation through gradual reduction. The authors found that among smokers not willing to quit abruptly on a given quit date or not able to do this, the possibility of gradual reduction of smoking increases the success rate of varenicline $(32 \%)$ when compared with a placebo (7\%). These findings support the idea that regardless of the behavioral method, use of effective medication is crucial in smoking cessation.
We noted a high prevalence of psychiatric co-morbidities in smokers in the current study throughout the course of the study. Generally, the prevalences of current alcohol or drug abuse, and anxiety, depressive, bipolar and personality disorders range $22-32 \%$, as shown in a relatively recent systematic review ${ }^{18}$. Nicotine-dependent smokers are 2.7 to 8.1 times more likely to be diagnosed with these disorders than non-dependent smokers, people who have never smoked, or ex-smokers ${ }^{18}$. Given this prevalence, the presence of these comorbidities must be considered in planning treatment of smoking addiction. Smokers may evaluate their discomfort during smoking cessation as withdrawal symptoms, which may interfere with successful cessation. There are several hypotheses that have been proposed to explain the high rates of comorbidity. On the one hand the self-medication hypothesis postulates that individuals turn to smoking to alleviate their symptoms and therefore suggests that symptoms of depression and anxiety may lead to smoking ${ }^{18,19}$. An alternative hypothesis is that smoking may lead to depression or anxiety, increasing susceptibility to environmental stressors ${ }^{18}$.

Given the real life setting of the current study and based on our previous experience ${ }^{12}$, we consistently use treatment with serotonin uptake inhibitors in smokers exhibiting symptoms of anxiety or depression. The percentage of users of serotonin uptake inhibitors in both behavioral groups was higher than prevalence of anxiety reported. Use of serotonin uptake inhibitors during varenicline treatment did not diminish success rates in both groups.

Regarding stated reasons for not achieving abstinence, both behavioral groups cited several, but stressful situations, side effects and anxiety symptoms appeared to be higher in the TQD group than the CRS group. We hypothesize that in the TQD group smokers felt unable to quit smoking on the stipulated date, were frustrated and tried to find justification for continuing smoking.

The principal reason for not achieving abstinence in the CRS group was dropout, perhaps because these smokers were not able yet to give up the pleasure of smoking as promoted by the "cue restricted' position. After week 12 to week 52, reasons for relapse appeared quite similar between 
groups. In both groups, the principal reason was stressful situations, which require further understanding and may be related to tobacco use as a chronic relapsing substance use disorder that requires repeated treatment over time in many individuals ${ }^{3}$.

Although Brandon et al. ${ }^{20}$ had observed that varenicline reduced tonic craving levels and perceived reward from smoking compared with placebo, the period of analysis in this study was only 15 days. Gass et al. ${ }^{21}$ observed after 5 weeks that varenicline did not change cue-induced craving in smokers compared with placebo. These findings suggest that the clinical efficacy of varenicline is not mediated by changes in cue-specific craving during the pre-quit period. This may indicate the lack of a role of neurotransmission via the a $4 \beta 2$ nicotinic acetylcholine receptors (nAChRs) in mediating the conditioned incentive motivation by nicotine cue exposure. Nicotine exerts its reinforcing actions via activating $\mathrm{nAChRs}$. Among a wide number of $\mathrm{nAChR}$ subtypes, the a $4 \beta 2$ and $a 7 \mathrm{nAChRs}$ are the two major ones, accounting for about $95 \%$ of the entire nAChR population in the brain. There may be differential involvement of the a $4 \beta 2$ and a 7 nAChR subtypes in the process of nicotine dependence and tobacco addiction $^{22}$.

In smokers, the environmental cues related to smoking behavior including both distally situational contexts and proximal sensory cues such as the visual and olfactory stimuli associated with each puff elicit subjective states that can trigger smoking and nicotine-seeking behavior ${ }^{22}$. Considering the model of blocking cue-triggered nicotine behavior, it could be very interesting to postulate that 'cue restricted smoking' produces a certain degree of antagonism at the a 7 receptor, underlying the high success rate.

\section{Limitations}

The main limitation of this study is that it is based on observational and retrospective data, with historically different periods of data collection. Confounders related to time could include patient and provider characteristics, societal factors and others that could have led to improved outcomes in the more recent arm. So, our hypothesis should be tested in randomized controlled trials. Additionally, it must be noted that the cue-or none/cue-restricted smoking and the inclusion or exclusion of target quit date both distinguished the two treatments. Therefore, it is difficult to attribute treatment differences to any one of these components, an issue that should be disentangled in future studies.

\section{CONCLUSIONS}

The evidence from our study indicates that 'Cue Restricted Smoking' compared to the conventional 'Target Quit Day' method was associated with a significant increase in abstinence rates in smokers using varenicline both at 12 and 52 weeks.

\section{REFERENCES}

1. GBD 2015 Tobacco Collaborators. Smoking prevalence and attributable disease burden in 195 countries and territories, 1990-2015: a systematic analysis from the Global Burden of Disease Study 2015. Lancet. 2017;389(10082):18851906. doi:10.1016/S0140-6736(17)30819-X

2. Rigotti NA, Clair C. Managing tobacco use: the neglected cardiovascular disease risk factor. Eur Heart J. 2013;34(42):3259-3267. doi:10.1093/eurheartj/eht352

3. Jarvis MJ. Why people smoke. BMJ. 2004;328(7434):277279. doi:10.1136/bmj.328.7434.277

4. Tobacco Use and Dependence Guideline Panel. Treating Tobacco Use and Dependence: 2008 Update. U.S. Department of Health and Human Services, Public Health Service; 2008. Accessed February 15, 2021. https://www. ncbi.nlm.nih.gov/books/NBK63952/

5. Anthenelli RM, Benowitz NL, West R, et al. Neuropsychiatric safety and efficacy of varenicline, bupropion, and nicotine patch in smokers with and without psychiatric disorders (EAGLES): a double-blind, randomised, placebocontrolled clinical trial. Lancet. 2016;387(10037):25072520. doi:10.1016/S0140-6736(16)30272-0

6. Cahill K, Stevens S, Perera R, Lancaster T. Pharmacological interventions for smoking cessation: an overview and network meta-analysis. Cochrane Database Syst Rev. 2013;(5):CD009329. doi:10.1002/14651858.CD009329.pub2

7. Coe JW, Brooks PR, Vetelino MG, et al. Varenicline: An a $4 \beta 2$ Nicotinic Receptor Partial Agonist for Smoking Cessation. J Med Chem. 2005;48(10):3474-3477. doi:10.1021/jm050069n

8. Jorenby DE, Hays JT, Rigotti NA, et al; Varenicline Phase 3 Study Group. Efficacy of Varenicline, an a4 32 Nicotinic Acetylcholine Receptor Partial Agonist, vs Placebo or Sustained-Release Bupropion for Smoking Cessation. JAMA. 2006;296(1):56-63. doi:10.1001/jama.296.1.56

9. Cahill K, Lindson-Hawley N, Thomas KH, Fanshawe TR, Lancaster T. Nicotine receptor partial agonists for smoking cessation. Cochrane Database Syst Rev. 2016;2016(5):CD006103. doi:10.1002/14651858.CD006103.pub7

10. Krasnegor NA, ed. The Behavioral Aspects of Smoking. 
NIDA Research Monograph 26. National Institute on Drug Abuse; 1979. Accessed February 15, 2021. https:// archives.drugabuse.gov/sites/default/files/monograph26. pdf

11. Ebbert JO, Croghan IT, Sood A, Schroeder DR, Hays JT, Hurt RD. Varenicline and bupropion sustained-release combination therapy for smoking cessation. Nicotine Tob Res. 2009;11(3):234-239. doi:10.1093/ntr/ntn031

12. Issa JS, Abe TO, Moura S, Santos PC, Pereira AC. Effectiveness of coadministration of varenicline, bupropion, and serotonin reuptake inhibitors in a smoking cessation program in the real-life setting. Nicotine Tob Res. 2013;15(6):1146-1150. doi:10.1093/ntr/nts230

13. Reid JL, Hammond D, Tariq U, Burkhalter R, Rynard VL, Douglas O. Tobacco Use in Canada: Patterns and Trends, 2019 Edition. Propel Centre for Population Health Impact, University of Waterloo; 2019. Accessed February 15, 2021. https://uwaterloo.ca/tobacco-usecanada/sites/ca.tobacco-use-canada/files/uploads/files/ tobacco_use_in_canada_2019.pdf

14. Lindson N, Klemperer E, Hong B, Ordóñez-Mena JM, Aveyard P. Smoking reduction interventions for smoking cessation. Cochrane Database Syst Rev. 2019;9(9):CD013183. doi:10.1002/14651858.CD013183.pub2

15. Wang MP, Li WH, Cheung YT, et al. Brief Advice on Smoking Reduction Versus Abrupt Quitting for Smoking Cessation in Chinese Smokers: A Cluster Randomized Controlled Trial. Nicotine Tob Res. 2017;20(1):67-72. doi:10.1093/ntr/ntx026

16. Lindson-Hawley N, Banting M, West R, Michie S, Shinkins B, Aveyard P. Gradual Versus Abrupt Smoking Cessation: A Randomized, Controlled Noninferiority Trial. Ann Intern Med. 2016;164(9):585-592. doi:10.7326/M14-2805

17. Ebbert JO, Hughes JR, West RJ, et al. Effect of varenicline on smoking cessation through smoking reduction: a randomized clinical trial. JAMA. 2015;313(7):687-694. doi:10.1001/jama.2015.280

18. Fluharty M, Taylor AE, Grabski M, Munafò MR. The Association of Cigarette Smoking With Depression and Anxiety: A Systematic Review. Nicotine Tob Res. 2017;19(1):3-13. doi:10.1093/ntr/ntw140

19. Chaiton MO, Cohen JE, O'Loughlin J, Rehm J. A systematic review of longitudinal studies on the association between depression and smoking in adolescents. BMC Public Health. 2009;9:356. doi:10.1186/1471-2458-9-356

20. Brandon TH, Drobes DJ, Unrod M, et al. Varenicline effects on craving, cue reactivity, and smoking reward. Psychopharmacology (Berl). 2011;218(2):391-403. doi:10.1007/s00213-011-2327-z

21. Gass JC, Wray JM, Hawk LW, Mahoney MC, Tiffany ST. Impact of varenicline on cue-specific craving assessed in the natural environment among treatment-seeking smokers. Psychopharmacology (Berl). 2012;223(1):107116. doi:10.1007/s00213-012-2698-9

22. Stoker AK, Markou A. Neurobiological Bases of Cue- and
Nicotine-induced Reinstatement of Nicotine Seeking: Implications for the Development of Smoking Cessation Medications. Curr Top Behav Neurosci. 2015;24:125-154. doi:10.1007/978-3-319-13482-6_5

\section{CONFLICTS OF INTEREST}

The authors have each completed and submitted an ICMJE form for disclosure of potential conflicts of interest. The authors declare that they have no competing interests, financial or otherwise, related to the current work. S. Tonstad reports grants from Pfizer, the manufacturer of varenicline, outside the submitted work.

\section{FUNDING}

There was no source of funding for this research.

\section{ETHICAL APPROVAL AND INFORMED CONSENT}

Ethical approval was received from Hospital das Clinicas, Universidade de São Paulo ethics committee (number SDC 3750/12/2016).

\section{PROVENANCE AND PEER REVIEW}

Not commissioned; externally peer reviewed. 